8.

Historia del Derecho 



\title{
Luis De Molina y Morales (C. 1520-1581) Y El "Código Civil de Chile”*
}

["Luis de Molina y Morales (c. 1520-1581) and the "Chilean Civil Code"”]

\author{
JAVIER BARRIENTOS GRANDON** \\ Universidad Autónoma de Madrid, España
}

\begin{abstract}
RESUMEN
Se examina en este artículo la influencia de los De hispanorum primogeniis libri quatuor, del jurista español Luis de Molina y Morales, en el proceso de formación del Código Civil chileno (1855), a través del análisis de las notas que lo indican como fuente de ciertos artículos suyos en materia de aceptación de la herencia.
Palabras Clave
Luis de Molina y Morales - Código Civil de Chile.

\begin{abstract}
This Article examines the influence of the De hispanorum primogeniis libri quatuor by the Spanish jurist Luis de Molina $y$ Morales in the process of formation of the Chilean Civil Code (1855) by way of the analysis of the notes that indicate he is the author of some articles in the matter of inheritance acceptance.

KeYwords

Luis de Molina y Morales - Chilean Civil Code.
\end{abstract}

RECibido el 20 de enero y APROBADo el 10 de abril de 2012.

* Este trabajo ha sido ejecutado en el marco del Proyecto Fondecyt Regular No 1095005, "El derecho castellano-indiano como fuente del Código Civil chileno", que el autor agradece.

** Académico de número de la Academia Chilena de la Historia, Investigador Ramón y Cajal, Facultad de Derecho Universidad Autónoma de Madrid, Doctor en Derecho por la Universidad de Castilla La Mancha. Dirección postal: Cortes de Aragón 50, $5^{\circ}$ D, 50005 Zaragoza, España. Dirección electrónica: javier.barrientos@uam.es 


\section{INTRODUCCIÓN}

El estudio que en los últimos años se ha hecho de los inventarios de las bibliotecas de los letrados de las Indias comprueba la enorme difusión de que gozaron durante los siglos XVII, XVIII y las primeras décadas del siglo XIX las obras de buena parte de los juristas hispanos de esas mismas centurias ${ }^{1}$.

La práctica judicial en las Audiencias habitualmente comprueba que esas obras también eran utilizadas con frecuencia por los abogados en el curso de los pleitos²; y hay también abundantes testimonios de la pervivencia de su empleo con posterioridad a los procesos de independencia política en Hispano América; uno de los más significativos es el de su utilización en los diversos procesos codificadores del siglo XIX ${ }^{3}$.

En el caso de la codificación civil chilena, uno de los tratadistas hispanos cuyas obras se tuvieron a la vista por Andrés Bello en el momento de la formación del Código Civil, que acabaría promulgándose en 1855, fue Luis de Molina y Morales, a través de su De hispanorum primogeniis, que fue uno de los tratados clásicos en la materia de mayorazgos y es a esta influencia a la que se destinará este breve artículo.

\section{Noticia BIO-BIBliográficA De Luis De Molina y MoRAleS}

Este jurista bético, todavía en muchas ocasiones confundido con el célebre jesuita conquense homónimo, nació en Osuna hacia 1520 en el seno de una familia de la pequeña nobleza en la que, por línea materna, contaba entre sus ascendientes a Ambrosio de Morales, y murió en Madrid en 1581 $1^{4}$. Estudió en la Universidad de Salamanca, en la que debió graduarse de bachiller en

${ }^{1}$ Además de los diversos trabajos sobre bibliotecas en particular, hay exposiciones generales; entre ellas, para letrados de la Nueva España, véase: BARRIENTOS GRANDON, Javier, La cultura jurídica en la Nueva España. Sobre la recepción de la tradición jurídica europea en el virreinato (Méjico, 1993); para Charcas: Rípodas ARDANAz, Daisy, Bibliotecas privadas de funcionarios de la Real Audiencia de Charcas, en Memoria del II Congreso Venezolano de Historia (18 al 23 de noviembre de 1974) (Caracas, 1975), II, pp. 501-555; para el reino de Chile, del mismo BARRIEntos Grandon, Javier, La cultura jurídica en el reino de Chile. Bibliotecas de ministros de la Real Audiencia de Santiago (s. XVII-XVIII) (Santiago de Chile, 1992).

${ }^{2}$ Véase: Barrientos Grandon, Javier, "Mos italicus" y praxis judicial en Indias, en Ius Fugit, 5-6 (Zaragoza, 1996-1997), pp. 359-430.

${ }^{3}$ GuZmán BRITo, Alejandro, Andrés Bello codificador. Historia de la fijación y codificación del derecho civil en Chile (Santiago de Chile, 1982), I, pp. 416-418.

${ }^{4}$ Sigo en esta reseña la biografía de Molina y Morales contenida en BARRIEntos GRANDON, Javier, Los consejeros del rey (en prensa en Madrid). 
cánones ${ }^{5}$, y consta que se graduó de licenciado en la misma facultad por la Universidad de Sevilla en el mes de mayo de $1547^{6}$. Una vez concluidos sus estudios se estableció en Madrid y allí se dedicó al patrocinio de causas, hasta que en 1562 se le hizo merced de la fiscalía de la Contaduría Mayor de Hacienda ${ }^{7}$.

Fue promovido a una plaza de consejero en el Consejo Real de Indias, de la que se le libró título por real cédula despachada el 22 de octubre de $1564^{8}$; y tres años más tarde, con licencia real, pasaba unos meses a Osuna a ocuparse en asuntos de su familia ${ }^{9}$ en enero de 1569 pasaba a Torrejón de Velasco a tomar confesión al marqués del Valle ${ }^{10}$.

Finalmente se le dio una plaza en el Consejo Real de Castilla en lugar del fallecido licenciado don Juan Morales, de la que se le libró título por real cédula fechada en San Lorenzo el 5 de agosto de $1572^{11}$. Cinco años más tarde trabajaba una Allegatio en defensa de los derechos de Felipe II a la sucesión de los reinos de Portugal, que sería publicada en ese mismo año 1579, y casi de inmediato fue llamado a integrar la delegación castellana que pasó a Portugal $^{12}$. Se mantuvo en el servicio de su plaza en el Consejo Real hasta su muerte, tras la cual fue substituido por el doctor Fernández Cogollos ${ }^{13}$.

A la pluma de Molina y Morales se deben las siguientes obras:

$\left.1^{\circ}\right)$ De hispanorum primogeniis, libri quatuor, que fue uno de los más influyentes tratados sobre el mayorazgo, publicado en Madrid por Andrés de Angulo en 1573, reeditado en Medina del Campo (expensis Petri Landry, \& Ambrosii Duport) en $1587^{14}$, en Lyon por Pedro Landry en 1588 y allí mismo (apud Ioan. Baptistam Ciotti) en 1601'15, también en 1727 por Anisson y Possuel y por Pedro Bousquet y sus socios en 1749; y otra en Venecia, por Nicolás Pezzana, en 1757.

Mereció esta obra la publicación de unas Additiones seu illustrationes aureas, debidas a la pluma y trabajo de los doctores Baltasar Gilimón de la Mota y Antonio de la Cueva y Silva, editadas en Lyon, por Jacobo Prost, en

${ }^{5}$ Antonio, Nicolás, Bibliotheca Hispana Nova (Madrid, 1788), II, fol. 52.

${ }^{6}$ Archivo Histórico de la Universidad de Sevilla, libro 478, fol. 61v.

${ }^{7}$ Francisco Olmos, José María, Los miembros del Consejo de Hacienda en el siglo XVII (Madrid, 1999), p. 126 n. 391.

${ }^{8}$ Archivo General de Simancas, "Quitaciones de Corte", leg. 32.

${ }^{9}$ Archivo General de Indias, "Indiferente General”, 425, 1. 24, fol. 391v-392r.

${ }^{10}$ Ibíd., fol. 447r.

${ }^{11}$ Archivo Histórico Nacional Madrid, “Consejos”, libro 707, fol. 156r.

${ }^{12}$ Antonio, Nicolás, cit. (n. 5), II, fol. 52-53.

${ }^{13}$ Archivo Histórico Nacional Madrid, "Consejos", libro 707, fol. 184r.

${ }^{14}$ Para esta edición, véase: PÉrez PAstor, Cristóbal, La imprenta en Medina del Campo (Madrid, 1895), p. 252.

${ }^{15}$ Antonio, Nicolás, cit. (n. 5), II, fol. 52-53. 
1634 y reeditadas allí mismo en 1657; igualmente, formó y dio a la imprenta otras Additiones et observationes el licenciado José Maldonado y Pardo, publicadas en Madrid en 1667; en la edición de Lyon de 1677 se añadieron unas observaciones de Fernando Alfonso del Águila y Rojas.

$\left.2^{\circ}\right)$ Iuris allegatio pro Rege Catholico Philippo II ad successionem Regnorum Portugaliae, publicada en 1579, uno de cuyos ejemplares se conserva en la Biblioteca Nacional de España en Madrid y otro en la de la Real Academia de la Historia ${ }^{16}$. Nicolás Antonio citaba esta obra como manuscrito con la variante en el título: Pro successione regni Portugalliae allegationum ${ }^{17}$.

El De hispanorum primogeniis fue uno de los más influyentes tratados en sede de mayorazgos y gozó de una amplísima difusión en Europa y las Indias. $\mathrm{Hr}$ podido mencionar su presencia en las bibliotecas de tres obispos novohispanos del siglo XVIII, en las librerías del Colegio de San Pedro y San Pablo de México, en el Colegio Seminario de la misma ciudad ${ }^{18}$; y se puede verificar su utilización en juicio ante la Real Audiencia de México ${ }^{19}$. En relación con el reino de Chile, he identificado su presencia en las bibliotecas de los oidores Pedro Machado de Chaves (1590-1647), Francisco Ruiz de Berecedo (16741746), José Clemente de Traslaviña y Oyagüe (1714-1780) y en la del regente Francisco Antonio Moreno y Escandón (1736-1792)20 datos a los que se puede agregar que también lo poseía, en su edición de León de 1749, el doctor Bernardo de Vera y Pintado (1780-1827) ${ }^{21}$; y que entre los actuales fondos de la Biblioteca Nacional de Chile se conservan sus ediciones de León de 1588 (8-341-5); de Colonia en 1601 (8-315-3) en un ejemplar que perteneció a la biblioteca de Mariano Egaña; de Venecia de 1757 (8-656-6 y 8-579-3) duplicada, una de las cuales también procedía de la misma biblioteca citada.

\section{Luis de Molina y MoRAles y la ACEPTACión DE LA HeRENCIA eN EL “Código Civil" de Chile}

El Proyecto de Código Civil de 1841, en su libro De la sucesión por causa de muerte contenía un título $14^{\circ}$ referido a los Derechos de los herederos, le-

\footnotetext{
${ }^{16}$ Se ocupa en el examen de esta Allegatio, de acuerdo con el ejemplar conservado en la Real Academia, Rodríguez GiL, Magdalena, La "incorporación” de reinos. Notas y textos doctrinales del Derecho Común (Cáceres, 2002), pp. 85-245.

${ }^{17}$ Antonio, Nicolás, cit. (n. 5), II, fol. 52-53.

${ }^{18}$ Barrientos Grandon, Javier, La cultura jurídica, cit. (n. 1), p. 192.

${ }^{19}$ Ibíd., pp. 258-259.

${ }^{20}$ Barrientos Grandon, Javier, La cultura jurídica, cit. (n. 1), pp. 64, 139, 247 , $388,468$.

${ }^{21}$ Barrientos Grandon, Javier - Rodríguez Torres, Javier, La biblioteca jurídica antigua de la Facultad de Derecho de la Universidad de Chile, en Revista de Estudios Histórico-Jurídicos, 14 (Valparaíso, 1991), pp. 291-334.
} 
gatarios $i$ acreedores, que se abría con el siguiente artículo 1: "La aceptación del heredero retrotrae al momento de la delación de la herencia los derechos en que sucede al difunto./ Pero en la berencia desde un dia cierto, no se adquiere el derecho a los frutos sino desde ese dia"22.

Tal disposición fue introducida en el "Proyecto de 1846" dentro del título $7^{\circ}$ De la aceptación i repudiación, con una serie de alteraciones, como artículo 249: "La aceptación i la repudiación se retrotraen al momento de la delación. La aceptación produce los mismos efectos que si el aceptante hubiese notificado su voluntad en el momento de deferirsele la asignación; $i$ la repudiación produce los mismos efectos que si el repudiante hubiese fallecido antes de la delación./ Lo cual se entiende sin perjuicio de lo dispuesto en el articulo $308^{\prime 23}$.

La disposición, que tampoco iba acompañada de notas, sufrió importantes modificaciones durante el proceso codificador; y así, en el Proyecto de Código Civil de 1853, se la mantuvo dentro del título $7^{\circ}$ : De la aceptación $i$ repudiación situada, asistemáticamente, en su $\$ 4$ De la petición de herencia $i$ de otras acciones del heredero, bajo el número 1443 con esta redacción: "La aceptación de una herencia continúa la persona del difunto en el heredero, con efecto retroactivo hasta la delación de la herencia./ Por consiguiente, todos los derechos del difunto sobre las cosas hereditarias, i la posesión misma, se entienden pasar al heredero desde la muerte de su antecesor". Pero, a diferencia de los casos anteriores, el texto estuvo acompañado de una nota que reza: "Véase Molina, De primog.: 1. 3, cap. 12, num. 6. Alli se verá que la disposición de este artículo es enteramente conforme a varios antiguos estatutos de Italia $i$ Francia, como lo es al Código Francés, artículo 1006, aunque con la diferencia de herederos lejitimarios i legatarios universales que nosotros no conocemos" ${ }^{24}$.

El texto de Molina y Morales referido en la nota llevaba por título: "Lex 45 Tauri, quid ultra Galliae \& Italiae originem sumpsit”, y representa un interesantísimo caso de utilización de fuentes por parte de Andrés Bello, pues en el examen de ella se pueden advertir los siguientes procesos:

a) Recurso a una fuente de sede particular que se extiende a un a sede gen eral. En efecto, Molina y Morales destinaba el citado capítulo $12^{\circ}$ del libro III de su De hispanorum primogeniis, al tratamiento del modo y manera en que, una vez muerto el último poseedor del mayorazgo, se transferían, ipso iure, al siguiente sucesor el dominio y la posesión civil y natural

${ }^{22}$ Bello, Andrés, Obras completas (reimpresión, Santiago de Chile, 1932), III: Proyecto de Código Civil, I, p. 151. También en Bello, Andrés, Obras completas de Andrés Bello (Caracas, 1955), XIII: Código Civil de la República de Chile. Introducción y notas de Pedro Lira Urquieta, II, p. 246.

${ }^{23}$ Bello, Andrés, cit. (n. 22), I, p. 379; Bello, Andrés, cit. (n. 22), II, p. 246.

${ }^{24}$ Bello, Andrés, Obras completas (reimpresión, Santiago de Chile, 1932), IV: Proyecto de Código Civil, II, p. 345. 
de los bienes del mayorazgo ${ }^{25}$; es decir, una fuente referida específicamente a la sucesión en los mayorazgos la empleaba el codificador en la sede general de la sucesión y esto era posible porque en esa sede particular se aplicaba el principio que la disposición codificada sentaba como general.

b) Recurso a una fuente que comprueba la confirmación del derecho vigente en la disposición codificada. El principio consagrado por Bello en el artículo 1443 del "Proyecto de 1853" era el que los juristas hispanos deducían y explicaban a propósito de la ley 45 de Toro, recibida en la "Nueva Recopilación de Castilla" de 1567 (5,7,8) y que extendía la disposición de las Siete Partidas $(5,4,7)$ relativa al traspaso de la posesión al heredero, tal cual lo explicaba Molina y Morales al decir que la citada ley de Toro podía haber tomado su origen de muchas leyes y estatutos italianos y galos, conforme con los cuales la posesión del difunto se continuaba en el heredero desde que realizara algún acto de aprehensión ${ }^{26}$, es decir, lo que en el lenguaje del "Proyecto de 1853" representaba un caso de "aceptación tácita” al tenor de sus artículos 1404, 1407 y 1408.

c) Recurso a una fuente del derecho propio para confirmar la disposición codificada con el ejemplo de un derecho propio extraño. Las mismas palabras de Bello en la nota dan cuenta de la función asignada a la obra de Molina y Morales: "Alli se verá que la disposición de este articulo es enteramente conforme a varios antiguos estatutos de Italia $i$ Francia" ${ }^{27}$ pues, precisamente, ese autor dedicaba el pasaje referido por Bello a explicar las disposiciones estatutarias de aquellas dos regiones, de las que decía podía traer su origen el principio asumido por el derecho castellano en la Ley 45 de Toro ${ }^{28}$.

d) Recurso a una fuente del derecho propio para destacar un diferencia entre la disposición codificada y un derecho extraño codificado. Esta función de la referencia a Molina fue puesta de manifiesto por el propio Bello cuando, tras remitir a la obra del jurista hispano y a la concordancia entre el principio asumido en el artículo 1443

${ }^{25}$ Molina, Luis, De hispanorum primogeniorum origine ac natura libri quatuor (Coloniae, apud Ioan, Baptistam Ciotti, 1601), lib. III, cap. 12, fol. 421: “2ualiter mortuo ultimo Maioratus possessore in sequentem successorem dominium atque possessio civilis \& naturalis bonorum Maioratus ipso iure transferuntur".

${ }^{26}$ Ibíd., lib. III, cap. $12^{\circ}$, n. 6, fol. 421: "Quae lex [ 45 de Toro] in eo, quod de translatione possessionis disposuit ultra praedictam legem partitarum [5,4,7] a pluribus etiam legibus, atque statutis Gallaiae \& quasi totius Italiae originem assumere potuit, ex quibus dispositum est, ut possessio defuncti in haeredem absque aliquo actu aprehbensionis continuetur, prout refert Tiraquellus in Tracta. le mort saisit le vif in praefatione secunda declarati. nu. I, ubi plures quaest. Subiungit [...]”.

${ }^{27}$ BELlo, Andrés, cit. (n. 24), II, p. 345.

${ }^{28}$ Véase Molina, Luis de, cit. (n. 25). 
del proyecto con los estatutos de Italia y de Francia, advertía que: "Alli se verá que la disposición de este artículo es enteramente conforme a varios antiguos estatutos de Italia i Francia, como lo es al Código Francés, artículo 1006, aunque con la diferencia de herederos lejitimarios i legatarios universales que nosotros no conocemos" ${ }^{29}$, pues, efectivamente, el originario artículo 1006 del Code Civil contenía la siguiente regla: "Lorsqu'au décés du testateur il n'y aura pas d'héritiers auxquels une quotité de ses biens soit réservée par la loi, le légataire universel sera saisi de plein droit par la mort du testateur, sans être tenu de demander la délivrance".

El principio asumido en el artículo 1443 del "Proyecto de 1853" no era más que el de la continuidad de la persona del difunto en su heredero, del que se derivaba el que la aceptación de la herencia se retrotraía al momento de su delación, que era, de acuerdo con el inciso $1^{\circ}$ del artículo 1114 del mismo "Proyecto", el "llamamiento de la ley a aceptarla o repudiarla" ${ }^{30}$, lo que se verificaba en el mismo momento de la muerte del causante, porque, el inciso $2^{\circ}$ del mencionado artículo 1114 del "Proyecto de 1853 " precisaba que: "La herencia o legado se defiere al heredero o legatario en el momento de fallecer la persona de cuya sucesión se trata, si el heredero es llamado puramente o a día cierto; o en el momento de cumplirse la condición, si es llamado condicionalmente" 31 , advirtiéndose que tal noción de "delación" era la propia del derecho vigente en Chile, como lo confirmaba la nota puesta por Bello a este artículo, que remitía a las Siete Partidas $(6,9,21)$.

En el llamado "Proyecto Inédito", la disposición anterior fue resituada, pues se la colocó en el título $7^{\circ}$ : De la apertura de la sucesión, i de su aceptación, repudiación e inventario, dentro de su $₫ 1$ : Reglas generales, como su artículo final y con una redacción diversa a la del proyecto precedente, pero sin alterar su contenido. En efecto, el artículo 1394 j dijo: "Los efectos de la aceptación o repudiación de una herencia se retrotraen al momento en que ésta haya sido deferida./ Otro tanto se aplica a los legados de especie"32.

La eliminación en el inciso $1^{\circ}$ de la referencia que el correspondiente del "Proyecto de 1853" hacía a que la aceptación "continúa la persona del difunto en el heredero" se explicaba porque ahora se había incluido bajo la misma regla a la repudiación y, además, porque esa consecuencia jurídica de la aceptación quedaba precisada en los artículos 1111 y 1114 del mismo "Proyecto Inédito".

Finalmente, ese artículo 1394 j se convirtió, sin alteración alguna, en el

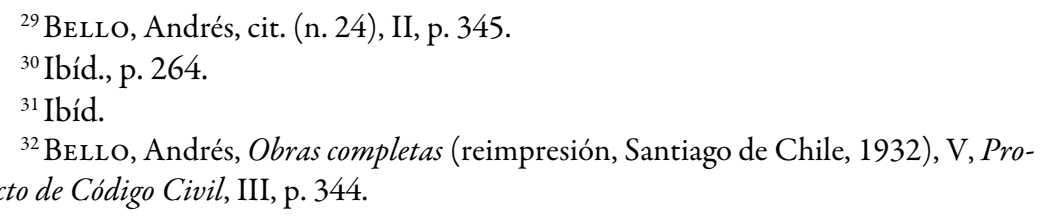


artículo 1239 del Código Civil promulgado en 1855 y en vigor desde el 1 de enero de 1857 hasta la actualidad y con ello, aún es posible apreciar en el texto vigente la influencia de la obra de Molina y Morales en los términos que quedan citados.

\section{ConClusión}

El examen precedente permite concluir, no sólo que uno de los actuales artículos en vigor del Código Civil chileno (artículo 1239) reconoce como fuente a un pasaje de la obra de Molina y Morales, sino también que Andrés Bello recurría a las obras de los juristas castellanos con finalidades diversas, y así, en el caso que se ha analizado, la cita al De hispanorum primogeniis cumplía las funciones de demostrar que la disposición codificada venía a confirmar el derecho vigente, a ofrecer una razón adicional para fundar la decisión codificada al apoyarla en el ejemplo de derechos extraños alegados por la fuente del derecho propio, y a destacar una diferencia entre la decisión codificada y la de otro derecho codificado.

\section{Bibliografía}

Antonio, Nicolás, Bibliotheca Hispana Nova (Madrid, 1788), II.

BARrientos Grandon, Javier - Rodríguez Torres, Javier, La biblioteca jurídica antigua de la Facultad de Derecho de la Universidad de Chile, en Revista de Estudios Histórico-Jurídicos, 14 (Valparaíso, 1991).

Barrientos Grandon, Javier, "Mos italicus" y praxis judicial en Indias, en Ius Fugit, 5-6 (Zaragoza, 1996-1997).

BARrientos Grandon, Javier, La cultura jurídica en el reino de Chile. Bibliotecas de ministros de la Real Audiencia de Santiago (s. XVII-XVIII) (Santiago de Chile, 1992).

Barrientos Grandon, Javier, La cultura jurídica en la Nueva España. Sobre la recepción de la tradición jurídica europea en el virreinato (Méjico, 1993).

Barrientos Grandon, Javier, Los consejeros del rey (en prensa en Madrid).

Bello, Andrés, Obras completas (reimpresión, Santiago de Chile, 1932), III: Proyecto de Código Civil, I.

Bello, Andrés, Obras completas de Andrés Bello (Caracas, 1955), XIII: Código Civil de la República de Chile. Introducción y notas de Pedro Lira Urquieta.

Francisco Olmos, José María, Los miembros del Consejo de Hacienda en el siglo XVII (Madrid, 1999).

GuZmán Brito, Alejandro, Andrés Bello codificador. Historia de la fijación y codificación del derecho civil en Chile (Santiago de Chile, 1982), I.

Molina, Luis, De hispanorum primogeniorum origine ac natura libriquatuor (Coloniae, apud Ioan, Baptistam Ciotti, 1601).

Pérez Pastor, Cristóbal, La imprenta en Medina del Campo (Madrid, 1895).

Rípodas Ardanaz, Daisy, Bibliotecas privadas de funcionarios de la Real Audiencia de 
Charcas, en Memoria del II Congreso Venezolano de Historia (18 al 23 de noviembre de 1974) (Caracas, 1975), II.

Rodríguez Gil, Magdalena, La “incorporación” de reinos. Notas y textos doctrinales del Derecho Común (Cáceres, 2002). 
